\title{
Knowledge and attitudes on smoking cessation techniques among healthcare professional students in Turkey
}

\author{
Ahmet Ergin ${ }^{1}$, Süleymon Utku Uzun², Ali Ihson Bozkurt ${ }^{3}$
}

\begin{abstract}
INTRODUCTION Smoking among adolescents and young adults is epidemic. This study aims to evaluate the rate of smoking and the knowledge and attitudes on smoking cessation techniques among healthprofession students in a University.

METHODS This cross sectional study was conducted among 338 (70.4\%) first 3-year students of the Faculty of Medicine (FM) and the School of Physical Therapy and Rehabilitation (SPTR) in Pamukkale University during January 2010.

RESULTS A total of 338 students participated in the study; 177(52.4\%) from the FM and 161 (47.6\%) from SPTR. Of all smokers (20.8\%), 14.9\% were current smokers. The prevalance of current cigarette smoking was higher among male students $(22.9 \%)$ than female students $(6.1 \%)(\mathrm{p}<0.001)$. The prevalance of current cigarette smoking increased significantly with age $(\mathrm{p}<0.001)$ and grade $(p=0.029)$. Students who had smokers in their family $(19.3 \%)$ were more likely to smoke than others (10.1\%) ( $\mathrm{p}=0.001) .36$ students $(76.6 \%)$ have tried to quit smoking and $29(60.4 \%)$ wanted to quit smoking in these days. $45.5 \%$ showed middle and higher nicotine dependence. $56.4 \%$ found useful to consider an on-campus smoking cessation clinic and $57.2 \%$ found the idea of peer-assisted smoking cessation useful.

conclusions On campus smoking cessation clinics, and besides physicians and psychologists, peerassisted smoking cessations approach may be useful in the effort of smoking cessation of university students.
\end{abstract}

AFFILIATION

a Department of Public

Health, Faculty of

Medicine, Pamukkale

University, Denizli, Turkey

CORRESPONDENCE TO

Dr. Süleyman Utku UZUN

Pamukkale University

Faculty of Medicine

Department of Public

Health

Kinikli / Denizli / Turkey

Email: utkuuzun402@

gmail.com

Phone: 0090

05053902327

\section{KEYWORDS}

smoking cessation, Health Occupations, adolescent health, medical student

\section{INTRODUCTION}

Tobacco use among health professionals is particularly important in efforts to control the tobacco epidemic. Health professionals are not only responsible for primary health care and health education, but they are also often role models in their community ${ }^{1}$. The importance of providing sufficient information on the hazards of smoking and smokingrelated diseases, providing necessary tools and placing medical students in an active role have been discussed in previously published papers ${ }^{1-4}$. Unfortunately, the prevalence of smoking among medical students has been found high, and up to $48 \%$ of males and $22 \%$ of female medical students in different parts of the world ${ }^{1,2}$. Moreover, significant deficits have been found in the amount and type of training medical students receive on smoking $^{3}$. In light of the above, the purpose of this study was to evaluate the knowledge and attitudes on smoking cessation techniques among health-profession students in Pamukkale
University, Denizli, Turkey, during the 2009-2010 academic year.

\section{METHODS}

\section{Participonts}

The population of this study was recruited from all accessible first 3-year students studying in the Faculty of Medicine (N: 260) and the School of Physical Therapy and Rehabilitation (SPTR) (N: 220) in Pamukkale University, Denizli, Turkey, during January 2010. Prevalence of current cigarette smoking was considered $20 \%$ with reference to the results of previous studies conducted among medical students in Turkey. The minimum sample size for study was calculated as 127 for medical faculty students and 117 for physical therapy and rehabilitation school students by using the formula of sample size $[\mathrm{n}=\mathrm{Nt} 2 \mathrm{pq} / \mathrm{d} 2(\mathrm{~N}-1)+\mathrm{t} 2 \mathrm{pq} ; \mathrm{a}=0.05, \mathrm{t}=1.96, \mathrm{~N}=260 \&$ 
220, $\mathrm{p}=0.20, \mathrm{q}=0.80, \mathrm{~d}=0.05]$. This cross-sectional survey was conducted among 177 (response rate: 68.1\%) medical faculty students and 161 (response rate: 73.2\%) physical therapy and rehabilitation school students. The study was approved by the Pamukkale University Ethics Committee, while consent was obtained from the participants after a brief explanation of the main aims of the study. The data was collected during normal class time.

\section{MEASURES}

An anonymous self-reported questionnaire was provided to participants, which contained domains on demographics and smoking parameters. The socio-economic status (SES) of the participant was determined by using the Family Affluence Scale $(\mathrm{FAS})^{5}$. The FAS score was determined by recoding the eight point scores ( 0 to 7 ) into three categories [low (0-3), middle (4-5) and high (6-7) FAS level] $]^{5}$. Nicotine dependence was measured by the Fagerström Nicotine Dependence Scale. A score of 8-10 or more indicated very high dependence; 6-7, high dependence; 5, medium dependence; 3-4, low dependence; and 0-2, very low dependence ${ }^{6}$.

Smoking status was defined with two questions: «Have you smoked at least 100 cigarettes in your entire life?» and «Do you now smoke cigarettes every day, some days or not at all?» Current smokers were defined as those who had smoked 100 cigarettes and now smoked either every day or some days.
Experimenting with smoking was defined by the answer to the question 'Have you ever tried smoking?'?

\section{STATISTICAL ANALYSIS}

Percentages and means were calculated. The chi-squared test was used to evaluate the potential associations. Statistical analyses were performed with SPSS version 10.0.

\section{RESULTS}

A total of 338 students participated in the study; 177 (52.4\%) from the Faculty of Medicine and 161 (47.6\%) from the SPTR. Males constituted $50.3 \%$ of the respondents and age range was between 17 to 25 years. Most (57.1\%) of the respondents had ever experimented with smoking. Twenty point eight percent had smoked at least 5 packs or more in their life time. Fifty ( $14.9 \%$ of all students) were current smokers, of which $37.1 \%$ started before the age of 15 .

The prevalence of current cigarette smoking was higher among male students than female students $(22.9 \%$ vs. $6.1 \%$, $\mathrm{p}<0.001)$. Smoking prevalence was similar among medical and SPTR students. The prevalence of current cigarette smoking increased significantly with age $(\mathrm{p}<0.001)$ and grade $(p=0.029)$. Although it was not statistically significant, students with low socioeconomic status had a higher current cigarette smoking prevalence (16.1\%) in comparison to students with middle (12.6\%) and higher (14.6\%) socioeconomic status

Table 1: Factors related to students'smoking (n=338)

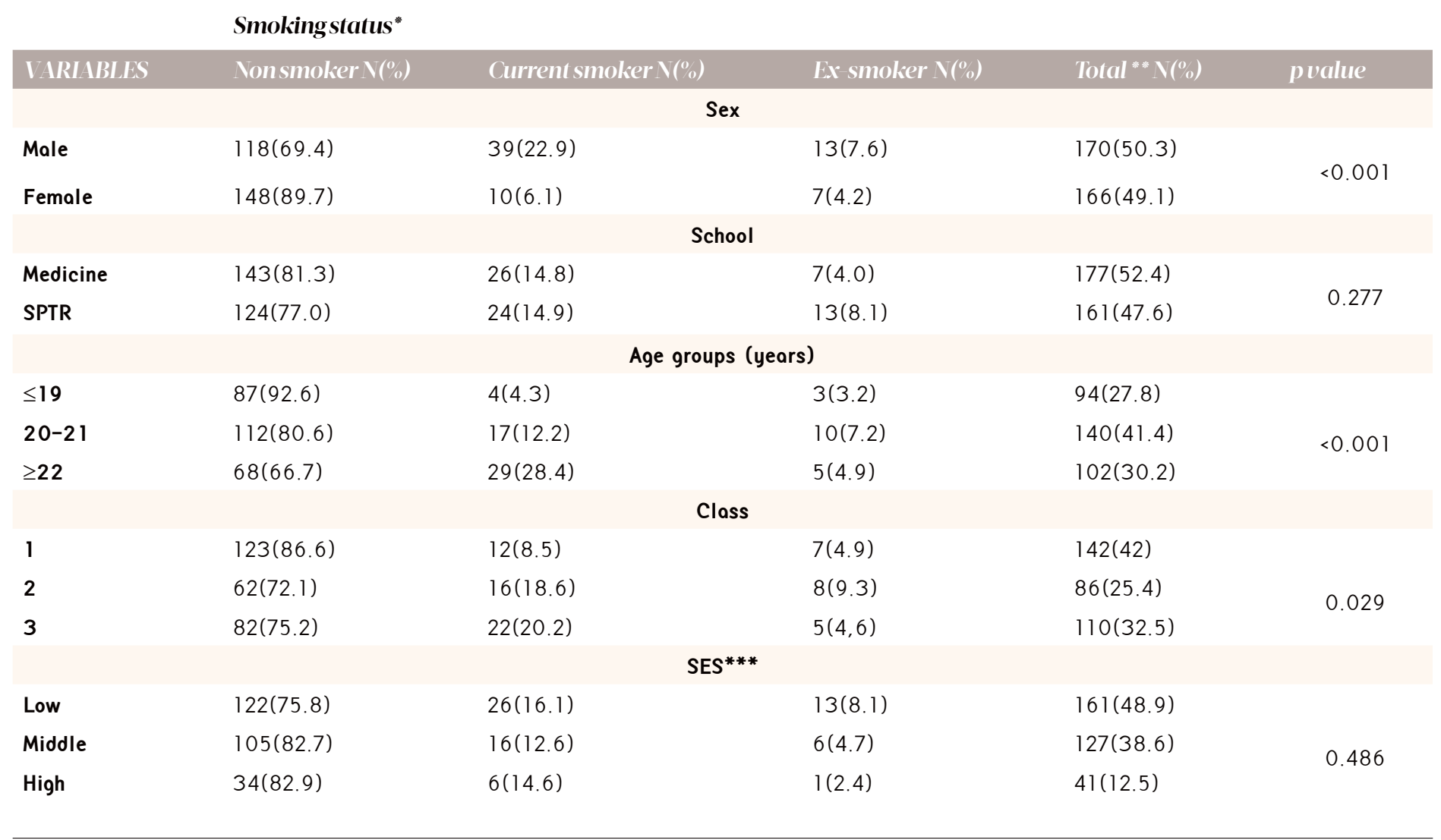




\begin{tabular}{|c|c|c|c|c|c|}
\hline \multicolumn{6}{|c|}{ Staying with } \\
\hline Family & $52(85.2)$ & $7(11.5)$ & $2(3.3)$ & $61(18.2)$ & \multirow{5}{*}{0.051} \\
\hline Dormitory & $87(88.8)$ & $6(6.1)$ & $5(5.1)$ & $98(29.3)$ & \\
\hline Relatives & $3(100.0)$ & $0(0.0)$ & $O(0.0)$ & $3(0.9)$ & \\
\hline Friends & $110(72.4)$ & $32(21.1)$ & $10(6.6)$ & $152(45.4)$ & \\
\hline Others & $14(66.7)$ & $5(23.8)$ & $2(9.5)$ & $21(6.3)$ & \\
\hline \multicolumn{6}{|c|}{ Smoking at family } \\
\hline No & $139(87.4)$ & $16(10.1)$ & $4(2.5)$ & $159(47.5)$ & \multirow{2}{*}{0.001} \\
\hline Yes & $126(71.6)$ & $34(19.3)$ & $16(9.1)$ & $176(52.5)$ & \\
\hline \multicolumn{6}{|c|}{ Smoking status of mother } \\
\hline No & $221(81.5)$ & $36(13.3)$ & $14(5.2)$ & $272(80.5)$ & \multirow{4}{*}{0.247} \\
\hline Exsmoker & $22(71.0)$ & $5(16.1)$ & $4(12.9)$ & $31(9.2)$ & \\
\hline Everyday & $19(70.4)$ & $7(25.9)$ & $1(3.7)$ & $8(2.4)$ & \\
\hline Sometimes & $5(62.5)$ & $2(25.0)$ & $1(12.5)$ & $27(27)$ & \\
\hline \multicolumn{6}{|c|}{ Smoking status of father } \\
\hline No & $119(85.6)$ & $18(12.9)$ & $2(1.4)$ & $140(41.4)$ & \multirow{4}{*}{0.004} \\
\hline Exsmoker & $62(73.8)$ & $15(17.9)$ & $7(8.3)$ & $84(24.9)$ & \\
\hline Everyday & $78(78.8)$ & $11(11.1)$ & $10(10.1)$ & $15(4.4)$ & \\
\hline Sometimes & $8(53.3)$ & $6(40.0)$ & $1(6.7)$ & $99(29.3)$ & \\
\hline \multicolumn{6}{|c|}{ Smoking status of siblings } \\
\hline No & $217(81.9)$ & $36(13.6)$ & $12(4.5)$ & $266(78.7)$ & \multirow{4}{*}{0.098} \\
\hline Exsmoker & $5(62.5)$ & $1(12.5)$ & $2(25.0)$ & $8(2.4)$ & \\
\hline Everyday & $41(69.5)$ & $12(20.3)$ & $6(10.2)$ & $5(1.5)$ & \\
\hline Sometimes & $4(80.0)$ & $1(20.0)$ & $0(0.0)$ & $59(17.5)$ & \\
\hline \multicolumn{6}{|c|}{ Smoking at home } \\
\hline $\begin{array}{l}\text { Not staying at } \\
\text { home }\end{array}$ & $67(87.0)$ & $4(5.2)$ & $6(7.8)$ & $77(23.6)$ & \multirow{3}{*}{$<0.001$} \\
\hline Yes & $44(54.3)$ & $32(39.5)$ & $5(6.2)$ & $81(24.8)$ & \\
\hline No & $146(86.9)$ & $14(8.3)$ & $8(4.8)$ & $168(51.5)$ & \\
\hline \multicolumn{6}{|c|}{ Passive exposure to smoke } \\
\hline None & $13(61.9)$ & $6(28.6)$ & $2(9.5)$ & $21(6.2)$ & \multirow{5}{*}{$<0.001$} \\
\hline Infrequently & $89(95.7)$ & $2(2.2)$ & $2(2.2)$ & $93(27.6)$ & \\
\hline Sometimes & $114(85.1)$ & $13(9.7)$ & $7(5.2)$ & $134(39.8)$ & \\
\hline Frequently & $34(72.3)$ & $11(23.4)$ & $2(4.3)$ & $47(13.9)$ & \\
\hline Everyday & $17(40.5)$ & $18(42.9)$ & $7(16.7)$ & $42(12.5)$ & \\
\hline
\end{tabular}

*Smoking status is defined by two questions: «Have you smoked at least 100 cigarettes in your entire life?» and «Do you now smoke cigarettes every day. some days or not at all?» Current smokers were defined as those who had smoked 100 cigarettes and now smoked either every day or some days.

** Some total do not addup because of missing data.

*** The socio-economic status (SES) of the participant was determined by using the Family Affluence Scale.

( $\mathrm{p}=0.486)$. Students who shared an apartment with his/ her friends $(21.1 \%)$ had higher current cigarette smoking prevalence than all other groups $(\mathrm{p}=0.05)$. Students who had smokers in their family were also more likely to smoke than others ( $19.3 \%$ vs. $10.1 \%, \mathrm{p}=0.001)$; likewise, students exposed to passive smoking everyday had higher current cigarette smoking prevalence (42.9\%) than exposed frequently $(23.4 \%)$, sometimes $(9.7 \%)$, infrequently $(2.2 \%)$ and non-exposed students $(28.6 \%, \mathrm{p}<0.001)$. (Table 1$)$

With regards to current smokers, $76.6 \%$ had ever attempted to quit smoking and $60.4 \%$ reported that they were currently interested in quitting, while $61.7 \%$ reported that they need 
help to quit smoking. Forty five point five percent of current smokers showed middle and higher nicotine dependence as assessed with the FNDS, 36.4\% low and $18.2 \%$ very low nicotine dependence. Knowledge of the types of smoking cessation aids varied as indicated in Table 2, with the most common aids, nicotine gum, patch and counselling. Fifty six point four percent of the current smokers noted that an on-campus smoking cessation clinic would be useful and $57.2 \%$ reported that peer-assisted smoking cessation would be useful. (Table 3)

Table 2: Knowledge and use of smoking cessation aids among health care students in Pamukkale University, Denizli, Turkey.

\begin{tabular}{lcc}
\multicolumn{2}{l}{ VIRINBLES } & n \\
Which method(s) of smoking cessation have you heard before?* \\
Consultation [Smoking cessation clinics] & 31 & 67.4 \\
Nicotine Spray & 19 & 41.3 \\
Nicotine Patch & 35 & 76.1 \\
Nicotine Gum & 38 & 82.6 \\
Acupuncture & 24 & 52.2 \\
Bupropion [Zyban] & 6 & 13.0 \\
Electronic cigarettes & 26 & 56.5 \\
$\quad$ Which method(s) of smoking cessation have you tried before?* \\
None & 37 & 80.4 \\
Consultation [Smoking cessation clinics] & 0 & 0 \\
Nicotine Spray & 0 & 0 \\
Nicotine Patch & 1 & 2.1 \\
Nicotine Gum & 3 & 6.4 \\
Acupuncture & 0 & 0 \\
Bupropion [Zyban] & 1 & 2.1 \\
Electronic cigarettes & 0 & 0
\end{tabular}

*Multiply answers are possible

\section{DISCUSSION}

Approximately one sixth of health-profession students in the university were current smokers. Smoking prevalence was higher among male gender, older age, those who share an apartment with his/her friends, having smokers in the family, paternal smoking, and exposure to passive smoking. While almost three quarters of smoking students have attempted to quit smoking in the past and approximately $2 / 3$ currently contemplating cessation, no one reported to have ever received medical advice on cessation and nearly half had never heard of smoking cessation clinics, which are the major establishment providing cessation resources in Turkey.

Several studies performed in similar populations indicated similar prevalence rates and risk factors for smoking. One study measured smoking prevalence of $19.0 \%$. While the smoking rate among the first year students was $15.6 \%$, the smoking rate among the sixth year students was $23.4 \%$. Another study noted that $18 \%$ of students were smoking every day, closer to the results of our study ${ }^{9}$. One larger study conducted in Turkey, in 2010 among 3rd year medical students in 12 medical schools found that almost 1 out of 5 students (19.3\%) were current cigarette smokers. Male students (29.3\%) were more likely than female students $(11.1 \%)$ to be current smokers ${ }^{10}$. Results of 2012 Global Adult Tobacco Survey (GATS) - in Turkey were also similar ${ }^{11}$ as $19.7 \%$ of the $15-24$ age group in Turkey were current cigarette smokers ${ }^{11}$.

We found that the prevalence of current cigarette smoking increased with age and grade. Previous studies carried out in Turkey and other countries have shown that smoking prevalence among medical students increases with age ${ }^{12-14}$. One study done in a medical faculty in Turkey found that students' smoking rate was $7.6 \%$ in the first year and $42.9 \%$ in the 6 th year $^{14}$. Another study carried out among health professionals in

Table 3: Answers to questions on the location and personnel of smoking cessation clinics

\begin{tabular}{|c|c|c|c|c|}
\hline \multicolumn{5}{|c|}{ What is the utility of the location of smoking cessation clinics to get advice on cessation methods? } \\
\hline Options* & Very useful & Useful & Not usefiul & Useless \\
\hline State Hospital n (\%) & $2(5.4)$ & $16(43.2)$ & $8(21.6)$ & $11(29.7)$ \\
\hline University Hospital n (\%) & $8(20.0)$ & $19(47.5)$ & $5(12.5)$ & $8(20.0)$ \\
\hline On-compus Clinic n (\%) & $9(23.1)$ & $13(33.3)$ & $10(25.6)$ & $7(17.9)$ \\
\hline Family physicians n (\%) & $7(18.9)$ & $8(21.6)$ & $10(27.0)$ & $12(32.4)$ \\
\hline \multicolumn{5}{|c|}{ What is your perceived utility of various professional groups in providing advice on smoking cessation methods? } \\
\hline Options* & Very useful & Useful & Not useful & Useless \\
\hline Doctor $n(\%)$ & $17(42.5)$ & $12(30.0)$ & $6(15.0)$ & $5(12.5)$ \\
\hline Nurse $n(\%)$ & $2(5.1)$ & $7(17.9)$ & $17(43.6)$ & $13(33.3)$ \\
\hline Psychologist $n(\%)$ & $22(51.2)$ & $16(37.2)$ & $1(2.3)$ & $4(9.3)$ \\
\hline Peer $n(\%)$ & $12(28.6)$ & $12(28.6)$ & $6(14.3)$ & $11(26.2)$ \\
\hline
\end{tabular}

*Among the current smokers who answered the specific option. 
2007, showed that $30.5 \%$ of general practitioners and $22.1 \%$ of specialists were current smokers ${ }^{15}$. Hence these results indicate that providing smoking cessation training during the first years of medical education seems to be important as the prevalence rate of smoking increases with age and grade of the students.

Most of the current smokers either had attempted to quit smoking in the past or were currently thinking of quitting. However, several factors are at play to preclude successful cessation. In view of the fact that half of the current smokers of our study were identified to have a middle or higher nicotine dependency; it can be argued that the poor success rate of self-quitting may be primarily due to elevated nicotine dependence ${ }^{16}$. Fortunately, effective forms of help are available including nicotine replacement therapy (NRT), bupropion and varenicline, as well as behavioral support ${ }^{17}$. In 1999, UK became the first country to establish a comprehensive national network of stop-smoking services (SSSs), providing a combination of medication and behavioral support ${ }^{18}$. In the US, the U.S. Public Health Service regularly publish updated guidelines on Treating Tobacco Use and Dependence, within which it is noted that tobacco-dependence interventions, if delivered in a timely and effective manner, significantly reduce the smoker's risk of suffering from smoking related disease ${ }^{19}$.

Turkey has over 20 year experience in smoking cessation clinics. The first clinic was opened in 1992. However the number and their effectiveness remained low until the end of the 1990's. Today, there are up approximately 228 clinics, and the number of smokers who use them have been increasing ${ }^{20}$. Additionally, the current study showed that besides services provided by physicians and psychologists, a significant number of students found potentially useful the idea of peer-assisted smoking cessation services. In fact, the peer-based interventions previously were proclaimed as a common method to affect important health-related behavioral changes $^{21}$. Therefore, peer-assisted smoking cessation may have a potential to be tapped.

There are several limitations of this study. First, we could not include other health profession students such as psychologists, nurses etc. in our study. However, we collected data from the two most prominent schools in this campus. Also, we could not reach 100 percent of students as originally planned. On the other hand, the study has several strengths such as the use of a population of students as the sample frame and a reasonable sample size that represented around two third of all eligible students that provides information on an topic for which limited regional information is available.

\section{CONCLUSIONS}

Approximately one sixth of health-profession students in the university were current smokers and most of them had tried and want to quit smoking. Smoking prevalence was higher among certain population groups. Smoking cessation clinics located in the student health centers may provide easy access to students especially those in the aforementioned risk groups, while «peer-assisted" smoking cessation must be explored as a potentially useful approach in smoking cessation among young people in university campuses. Overall, smoking among health-professional students should be targeted due to this behaviors impact on their health and potential impact to reduce their ability to deliver effective tobacco control messages to the community.

\section{REFERENCES}

1. WHO the GTSS Collaborative Group. Tobacco use and cessation counseling. Global health professionals survey pilot study, 10 countries. MMRW 2005;54(20): 505-509.

2. Richmond R. Teaching medical students about tobacco. Thorax 1999; 54 (1): 70-8.

3. Pederson LL, Blumenthal DS, Dever A, McGrady G. A web-based smoking cessation and prevention curriculum for medical students: why, how, what, and what next. Drug Alcohol Rev 2006; 25(1):3947.

4. Toriola, Adetunji T. Smoking behaviour and attitudes regarding the role of physicians in tobacco control among medical students in Kuopio, Finland in 2006. CVD Prevention and Control 2008; 3(2);53-60.

5. Currie CE, Elton RA, Todd J, Platt S. Indicators of socioeconomic status for adolescents: the WHO Health Behavior in School-aged Children Survey. Health Education Research 1997;12:385-397.

6. Heatherton TF, Kozlowski LT, Frecker RC, Fagerström KO. The Fagerström Test for Nicotine Dependence: a revision of the Fagerström Tolerance Questionnaire. British Journal of Addiction 1991;86:1119-1127.

7. Centers for Disease Control and Prevention. State-specific secondhand smoke exposure and current cigarette smoking among adults-United States, 2008. MMWR 2009;58:1232-1235.

8. Kutlu R, Civi S, Sahinli AS. The Frequency of Depression and Smoking Habit among the Medical Students. TAF Prev Med Bull 2009;8(6):489-496. (Turkish)

9. Yldrm C, Celik P, Sakar A, Dinc G. Medical school students' attitudes towards smoking. Respiration 2004;6(1): 30-35. (Turkish)

10. Inandi T, Caman OK, Aydin N, Onal AE, Kaypmaz A, Turhan E, et al. Global health professions student survey Turkey: second-hand smoke exposure and opinions of medical students on anti-tobacco law. Cent Eur J Public Health 2013;21(3):134-139.

11. The Ministry of Health of Turkey. Global Adult Tobacco Survey (GATS) Turkey Country Report 2012. Available from: http:// www.who.int/tobacco/surveillance/survey/gats/report_tur_2012. pdf?ua $=1$

12. Nguyen VH, Dao TM, Dao NP. Smoking among Vietnamese medical students: prevalence, costs, and predictors. Asia Pac J Public Health. 2008;20(1):16-24.

13. Almerie MQ, Matar HE, Salam M, Morad A, Abdulaal M, Koudsi A, et al. Cigarettes and waterpipe smoking among medical students 
in Syria: a cross-sectional study. Int J Tuberc Lung Dis. 2008 Sep;12(9):1085-1091.

14. Yoldascan E, Usal G, Ozdemir B, Akdemir S. Smoking prevalence and affecting factors among medical students in Cukurova University. VIII. National Public Health Congress booklet, 2002; pp. 802. (Turkish)

15. Aslan D, Bilir N, Ozcebe H, Erguder T. Smoking status of the health professionals and influencing factors, Ministry of Health, Ankara, 2008.

16. Brose LS, West R, McDermott MS, Fidler JA, Croghan E, McEwen A. What makes for an effective stop-smoking service? Thorax 2011;66:924-926.

17. West R, Shahab L. Smoking cessation interventions. In: Killoran A, Kelly M, eds.

Evidence-based public health effectiveness and efficiency. Oxford: University Press, 2009; pp. 215e32.

18. National Institute for Health and Clinical Excellence (NICE). Smoking cessation services in primary care, pharmacies, local authorities and workplaces, particularly for manual working groups, pregnant women and hard to reach communities. 2008, London. Avaliable from: http://www.nice.org.uk/nicemedia/pdf/ PH010guidance.pdf

19. Jaén CR, Benowitz NL, Curry SJ, Parsippany NJ, Kottke TE, Mermelstein RJ, et al. The clinical practice guideline treating tobacco use and dependence: 2008 update a US Public Health Service report. Am J Prev Med 2008;35(2):158-176.

20. Celik I, Yüce D, Hayran M, Erman M, Klçkap S, Buzgan T, et al. Nationwide smoking cessation treatment support program-Turkey project. Health Policy 2015;119(1):50-56.

21. Webel AR, Okonsky J, Trompeta J, Holzemer WL. Systematic review of the effectiveness of peer-based interventions on healthrelated behaviors in adults. Am J Public Health 2010;100:247-253.

ACKNOWLEDGEMENTS We would like to thank to Merve Korkut and Mübetcel Ocak for their help on data collection and analysis.

\section{CONFLICT OF INTEREST}

The authors have

completed and submitted the ICME Form for Disclosure of Potential Conflicts of Interest and none were reported.

FUNDING

There was no source of funding for this research.

PROVENANCE AND PEER REVIEW

Not commissioned:

externally peer reviewed 